International Journal of Engineering \&Technology, $8(4)(2019) 517-522$
International Journal of Engineering \& Technology
WPC
Website: www.sciencepubco.com/index.php/IJET
Research paper

\title{
The impact of information culture on the adoption of mobile cloud learning in higher education environments
}

\author{
Bassam A. Y. Alqaralleh ${ }^{1}$ *, Malek Zakarya Alksasbeh ${ }^{1}$, Tamer Abukhalil ${ }^{1}$, Harbi Almahafzah ${ }^{1}$ \\ ${ }^{1}$ Faculty of Information Technology, Al Hussein Bin Talal University, Jordan \\ *Corresponding author E-mail: alqaralleh@ahu.edu.jo
}

\begin{abstract}
Adoption of new innovated technologies has become an important requirement for a successful development and implementation of computer systems. Mobile cloud learning is a relatively recent paradigm shift that provides significant promise for meeting future education development and delivery requirements based on mobile cloud computing. The focal point of this study is to develop a conceptual model which highlights the effects of information cultural factors on the adoption of mobile cloud learning in higher education environments. The proposed model is developed based on four identified information cultural variables, namely information integrity, formality, control and pro-activeness. A pilot survey is conducted to test the questionnaire using a small sample of information systems experts and university lecturers. The results show acceptable reliability and validity of the instrument. Finally, conclusions, possible practical contributions of this study and some of the directions for upcoming research are discussed.
\end{abstract}

Keywords: Cloud Computing; Higher Education; Information Culture; Mobile Cloud Learning; Mobile Learning.

\section{Introduction}

The education institutions always seek for new and advanced technologies to facilitate online information and knowledge sharing among researchers, lecturers and students. The rapid progress of mobile technology and the high penetration rate of smart phones among students and the important development in information and communication technology (ICT) has increased researchers' interest in the adoption of mobile learning (ML) in education institutions [1]. ML has changed the education paradigm to help lecturers and students to organize and coordinate their interactions and to access online education materials and resources at any time and from anywhere [2,3]. ML refers to the use of mobile ICT technologies by education institutions to deliver their education services to students. The rapid diffusion of mobile technologies offered many new opportunities for mobilizing the interaction between researchers, lecturers and students by bringing the power of mobile networks into the connectivity gap between them.

NIST [4] defines cloud computing as, "A model for enabling convenience, on demand network access to a shared pool of configurable computing resources that can be rapidly provisioned and released with minimal management effort or service provider interactions". USA and Japan are good examples of developed countries that already use the recent technology of cloud computing to cut the cost of ICT infrastructure and IT-based services. In the education sector, cloud computing is carrying many important changes and new advances in teaching and learning. Several education institutions have employed ICT infrastructure to reduce the cost and to enhance teaching and learning process through building e- and m-portals for sharing knowledge and learning tools. Microsoft Office 365, Google Educator, iGoogle, Book Search, News, Google doc and Google Notebook are examples of well-known cloud-based applications that have been developed for teachers. These applications allow teachers and students to work freely and store their data in the "cloud". Moreover, their data will be accessible on a 24 x 7 basis without the need to carry any sort of disks (i.e. optical disks, SSD). Also, cloud computing can deliver several benefits to Higher Education Institutions (HEIs) such as reducing the cost of ICT infrastructure, effective access of several applications, set up websites and student portals with the help of various cloud features and characteristics such as virtual infrastructure, reliability, scalability, flexibility [5]. Furthermore, cloud computing can offer improved communications, data sharing and integrated enterprise library system among several HEIs. According to McREA [6], cloud computing offers more support for improving research and education as compared to earlier IT systems. Others [7] claimed that cloud computing can cut the complexity and difficulty of IT configuration.

Mobile cloud learning is an integration between mobile learning environment and cloud computing technologies [8], [9]. The use of mobile cloud learning technology in education has encouraged independent learning in the student community via increasing the widespread availability of knowledge. Also, education systems can be enhanced to provide more opportunities for part-time and distance learning students who suffer from lack of access to traditional education resources and libraries. Mobile and cloud computing technologies have enabled HEIs to provide more competitive world-class education system to realize the objective of quality education for all. Jordan is a good example of the developing countries that spend huge amount of money to build ICT infrastructure for education. The sector of higher education in Jordan contains around 10 public universities and about 17 private Universities. These universities invest millions of dollars 
every year in IT. However, HEIs in developing countries are still not capable to supply full ICT infrastructure requirements due to the struggling economy in these countries. Therefore, using cloud platforms and services for HEIs in developing countries will be beneficial in terms of reducing the cost of ICT and sharing resources [10].

Despite the advantages of cloud computing utilities and services, some education institutions have been considerably slow to adopt the cloud for their core academic services due to several important issues [11]. In developing countries, numerous challenges have been encountered by the adoption of mobile cloud learning services amongst the HEIs [12]. Such challenges include the lack of investigation for the impact of information culture factors on mobile cloud learning, particularly in Jordan. Information culture is defined by the authors in [13] as "patterns of behaviors and attitudes that express an organization's orientation toward information". The literature highlighted the importance of information culture as an important factor influencing the success of innovated information systems (IS) [14]. Mukred, et al. [15] claim that the absence of the information culture is one of the major challenges that face the development of ISs in organizations. Therefore, this study aims to propose a model to explore the information cultural factors impacting HEIs to adopt mobile cloud services. This proposed model uses four factors that represent the most important information behaviors and values. Information integrity, information formality, information control, and information pro-activeness are presented as influencing factors that directly affect the adoption of mobile cloud learning services in the Jordanian HEIs.

\section{Literature review}

Many researchers have recognized the importance of cloud computing in HEIs, Sultan [16] listed many HEIs in developed countries (i.e. USA, UK and Africa) that have adopted cloud computing. This extensive adoption indicates that cloud computing is playing an important role in enhancing learning system efficiency. However, there is a deficiency of studies that investigate the influencing factors of mobile cloud learning in higher education environments [17-19].

AlAjmi, et al. [5] proposed a model for adopting e-Learning systems based on cloud computing technology in HEIs. They focus on the internal organization factors such as DOI model, Fit-Viability model and information culture factors that may determine the adoption of this new innovated technology. However, the proposed constructs still need to be empirically validated. Liang, et al. [20] investigated the adoption of mobile technology according to the Fit-Viability model. Others [21] proposed another model to investigate the adoption of cloud computing technology as an alternative to implement e-government services. Their model was developed based on DOI and FitViability models. On the other hand, Masrom [22] examined the applicability of Technology acceptance model (TAM) in explaining students' acceptance of e-learning systems within the academic environments. The results indicate that TAM can be used to explain the students' acceptance of e-learning technology. Also, Sabi, et al [23] proposed a conceptual model for the adoption of cloud computing in education. Their model was developed based on TAM and DOI models. Another study [24] proposed a conceptual model for investigating the influence of information culture on the adoption of e-commerce systems. Their model was constructed from four information culture factors, namely information control, integrity, formality and proactiveness.

In the context of developing countries, building a more established information culture is necessary for encouraging the adoption of new emerging technologies. In order to strengthen successful adoption of new e-learning innovations, the specific capabilities for evaluating and utilizing information culture should be well addressed [25]. In Jordan, the effect of information culture on the adoption of mobile cloud learning services in higher education environments has not been addressed. On the other hand, information culture is still a challenging issue that can burden the adoption of mobile cloud learning technology in HEIs. Hence, the main aim of this study is investigating the impact of information culture factors on the adoption of mobile cloud learning in HEIs in Jordan.

\section{Conceptual model and research hypotheses}

Information culture is the standard in which intellectual resources are transformed and maintained alongside the transformation and maintenance of material resources [26]. Information culture is considered an important part of the organizational culture which focusses on information and ICT. It has a great influence on the way in which the organizations manage and use information [27]. Information Culture concentrates on effective information management and usage instead of focusing on machines. On the other hand, information technology, common knowledge, individual information systems (attitudes), and information ethics can be considered as the essential parts of information culture, which have an interactive role in affecting the way in which the organizations manage and make use of information [28], [29].

According to [5], information culture is one of the important factors that seem to have influence on the general acceptance of electronic learning (e-learning) services in developing countries. Also, the authors highlighted that such factor could be inspected further. Based on the related literature, numerous variables relevant to the information culture and e-learning adoption are selected to propose a conceptual framework and to develop the hypotheses. The proposed model includes four information cultural key constructs, namely information integrity, formality, control and pro-activeness. These four constructs represent the independent variables and intention to adopt mobile cloud learning as a dependent variable. Four hypotheses have been proposed, one for each independent variable in the model. As shown in Figure 1, the independent variables are proposed to have direct relationships with the intention to adopt mobile cloud learning which is the main dependent variable.

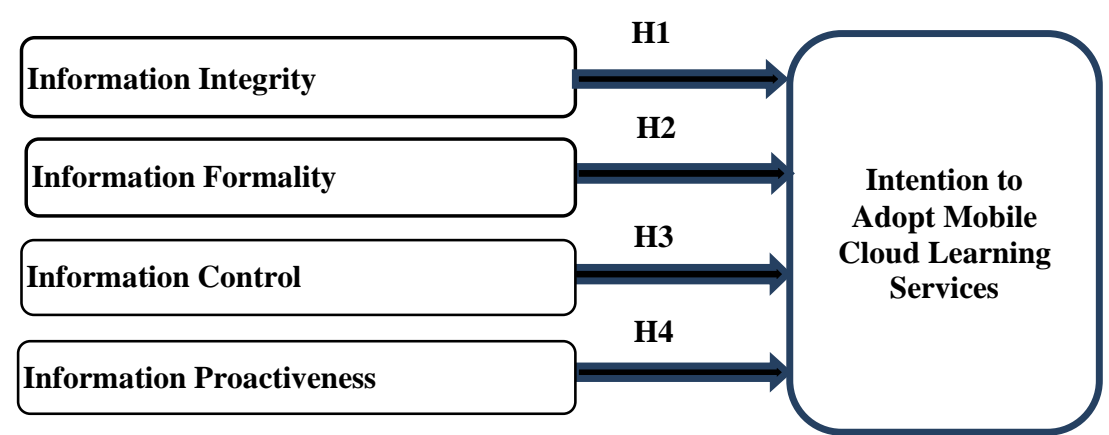

Fig. 1: The Proposed Conceptual Model. 


\subsection{Information integrity}

Information integration is defined as the trustworthiness and dependability of information [30]. More precisely, it is the consistency, reliability and accuracy of the content, system and processes of information. Enhancing information integration is also an important requirement for the success of business operations and activities [31]. It is important to mention that negative values could lead to unclear, confusing or unusable information which consecutively would most likely affect the process of decision making and could motivate negative manipulation of information that can be used for individual benefits. On the other hand, positive values will raise transparent information which may encourage trust in information flow and decision making [31]. Therefore, information integrity could positively have influence on the adoption of mobile cloud learning and it is hypothesized that:

H1: Information Integrity will positively affect the adoption of mobile cloud learning in the Jordanian HEIs.

\subsection{Information formality}

Information formality can be defined as the intentional dependence on regulated information [31]. Giving more attention to formal communications would most likely lead to rich documentation of procedures and processes, enhanced information quality and robust information formality [32].

Previous studies highlighted the importance of both formal and informal information systems to accomplish collaboration activities within organizations. The authors in [33] debated that information formality has a positive impact on information quality. Also, others [34] claimed that information formality is essential for the provision of formal information to help making decisions within organizations. Decision making is accomplished by using formal influences and communications with internal and external stakeholders to enhance the available formal information and confirm its consistency. Therefore, this study expects information formality to positively influence the stakeholders of HEIs in Jordan in their adoption of ML based on cloud computing. Consequently, the researchers recommend that: H2: Information formality will positively affect the adoption of mobile cloud learning in the Jordanian HEIs.

\subsection{Information control}

Information control refers to applying information in such a way that discourages or supports certain behaviors and practices [31]. The stakeholders should be able to monitor and control operational activities, exercises and decision making along with the utilization of data. Such abilities are important for acquiring optimal conduct, accomplishments and performance.

The information control mechanisms are mostly related to the personal performance which is connected to the organization performance [32]. Simons [35] established certain rules that encourage positive behavior and firm achievements. Furthermore, he clarified that positive information control encourages the employees to be more professional via their use of available information resources. This could lead to accepting the value of learning within the organization. Furness [32] reported that information control can be influenced by both information integrity and formality. Therefore, this study expects information formality to positively influence the stakeholders of higher education institutions in Jordan in their M-learning adoption. Consequently, the following hypothesis is proposed to be tested in this study: H3: Information control will positively affect the adoption of mobile cloud learning in the Jordanian HEIs.

\subsection{Information pro-activeness}

Information pro-activeness refers to an approach of a state of mind on how to choose and apply newly acquired information in a quick and appropriate manner in commercial domain in order to respond to dynamic business environment leading to advanced administration, products promotion and services innovation [31]. Paying special attention to the changing environment and expecting specific situations are two important activities of being proactive and both often involve exchange of information. Moreover, pro-activeness also embraced the willingness and the ability to understand and respond to the acquired knowledge. As indicated by [32], information pro-activeness would be subject to the influence of information integrity. In this study, information pro-activeness is expected to have a positive impact on the adoption of m-learning adoption as highlighted in the following proposed hypothesis:

H4: Information pro-activeness control will positively influence the adoption of mobile cloud learning in the Jordanian HEIs.

\section{Methodology}

A quantitative approach has been chosen for this study. This approach is used to validate the relationships in the proposed model among information culture variables as independent variables and the intent to adopt mobile cloud learning as a dependent variable. A survey was used to collect preliminary data for evaluating the proposed model. The survey instrument is extracted from earlier studies on IS adoption and acceptance as shown in Table 1.

Table 1: The Survey Constructs

\begin{tabular}{|c|c|c|}
\hline Construct & \#Items & References \\
\hline Information Integrity & 5 & [29] [24] [33] \\
\hline Information Formality & 5 & [29] [24] [33] \\
\hline Information Control & 5 & [29] [24] [33] \\
\hline Information Pro-activeness & 5 & [29] [24] [33] \\
\hline Adopt mobile based learning & 4 & [2] [36] [37] \\
\hline
\end{tabular}

A survey instrument consists of a total of (24) items have been adjusted by the researchers to fulfill the requirements and the purpose of the current study. These items are interpreted into Arabic language to help non-English language speaking respondents to understand and answer it. The questionnaire instrument is divided into two sections: Section 1 focused on the demographics of the participants and the Universities, while Section 2 covers the main study measures regarding information culture factors and adoption of ML based on cloud computing. The intention to adopt mobile cloud learning is measured in Section 2 of the instrument using a five-point Likert type scale (with responses ranging from $1=$ strongly disagree to $5=$ strongly agree). Five academic experts from the field of information and communication systems offered worthy feedback and comments to authenticate the structure of survey instrument and exclude ambiguous 
questions before applying the preliminary study. This preliminary study is conducted at most of Jordanian government and private Universities. The research team distributed the questionnaires to the managers of computer centers of the participating Universities.

The reliability of the research instrument is analyzed through Cronbach's alpha and composite reliability tests using SPSS statistical tool. Also, Structural Equation Modeling (SEM) done using the software tool SmartPLS. PLS-SEM method is used for preliminary data analysis to validate both the measurement and the structural components of the proposed model. The analysis results were utilized to estimate the indicator weights, the loadings for all instrument items and the structural (path) coefficients between the exogenous and endogenous variables. Moreover, convergent and discriminant validity tests are also assessed to confirm instrument validity.

\section{Preliminary study results}

In this study, the statistics of Cronbach's Alpha reliability test are used to estimate the degree of reliability of the research instrument, to guarantee that the items which have been used for each construct can measure its attributes, and to confirm that the outputs from the measurements are consistent over time [38]. Table 2 exhibits that the values of 's Alpha are above 0.9 for each construct, and the mean inter-item correlation values range from 0.564 to 0.876 . These results present well-structured model since it has an excellent level of internal consistency and it indicates adequate reliability for all constructs as recommended by $[39,40]$.

Table 2: Reliability Statistics

\begin{tabular}{|c|c|c|c|c|}
\hline Construct & \#Items & Min inter-item correlation & $\begin{array}{l}\text { Max inter-item cor- } \\
\text { relation }\end{array}$ & Cronbach's alpha \\
\hline Information Integrity & 5 & 0.723 & 0.820 & 0.922 \\
\hline Information Formality & 5 & 0.564 & 0.788 & 0.912 \\
\hline Information Control & 5 & 0.612 & 0.876 & 0.943 \\
\hline Information Pro-activeness & 5 & 0.632 & 0.855 & 0.932 \\
\hline Adopt mobile cloud learning & 4 & 0.714 & 0.833 & 0.939 \\
\hline Total & 24 & & & \\
\hline
\end{tabular}

The validity of the model is assessed using PLS-SEM analysis using Smart PLS. The results show that R-squared value is 0.82 . This shows that about $82 \%$ of the variance in user intention to adopt mobile cloud learning at the Jordanian Universities can be explained by the constructs in the proposed conceptual model.

To ensure valid and reliable results for the proposed model and instrument in the final study, it is necessary to determine the convergent and discriminant validity as well as the reliability. This allows confidential test of the causal (structural) model to determine whether the research hypotheses are supported or not. Reliability can be confirmed via the measurement of composite reliability (CR), the threshold should be more than 0.7. Then, convergent validity can be verified via the measurement of the Average Variance Extracted (AVE) for every construct [41]. Table 3 indicates that the values of AVE and CR for all constructs fall up the required threshold value (0.5).

Table 3: Construct AVE and Composite Reliability (CR)

\begin{tabular}{lrr}
\hline Construct & AVE & CR \\
\hline Information Integrity (II) & 0.843 & 0.943 \\
Information Formality (IF) & 0.923 \\
Information Control (IC) & 0.822 \\
Information Pro-activeness (IP) & 0.881 \\
Adopt mobile cloud learning (AMLCC) & 0.735 \\
\hline
\end{tabular}

In order to estimate the discriminant validity [42], Table 4 exposes the construct's correlations and the square root of AVE for all used constructs. The leading diagonal in Table 4 shows that the values of the square root of AVE are greater than the correlation values of all constructs indicating adequate discriminant validity [43].

Table 4: Construct Correlations and Square Root of AVE

\begin{tabular}{|c|c|c|c|c|c|}
\hline Construct & CII & $\mathrm{CIF}$ & CIC & CIP & AMLCC \\
\hline CII & 0.935 & & & & \\
\hline CIF & 0.715 & 0.946 & & & \\
\hline CIC & 0.712 & 0.599 & 0.874 & & \\
\hline CIP & 0.702 & 0.630 & 0.622 & 0.939 & \\
\hline AMLCC & 0.699 & 0.645 & 0.688 & 0.718 & 0.963 \\
\hline
\end{tabular}

\section{Discussion and conclusion}

Understanding the factors that may affect the adoption of mobile cloud learning in HEIs will help exploring the potential of estimating and predicting the success of adopting these technologies before applying them. The outcome results from this preliminary study have contributed important implications for HEIs to develop better plans to encourage the usage and the acceptance of mobile cloud learning technology.

For this study, the development of both the model and the instrument was the first stage to investigate the influence of information culture factors on adopting mobile cloud learning in Jordanian HEIs. In the second stage, the preliminary study was conducted through questionnaires distributed to most of Jordanian universities to collect data from the managers of the computer centers in those universities. In the third stage, the reliability of the model constructs based on preliminary data was verified since Cronbach's Alpha coefficient for all constructs falls above 0.7 [40]. In the fourth stage, the convergent and discriminant validity of all constructs was established with the help of AVE and CR statistics. The values of AVE and CR for all constructs fall above the recommended threshold [41]. Thus, these results provide initial support for the proposed conceptual model constructs and the instrument as a sound basis for evaluating the effect of information culture on the adopting mobile cloud learning services at the Jordanian Universities.

This study contributes to the existing literature and the current detailed understanding of how to build new technology adoption models that are related to the context of developing countries. Therefore, the results from the full-scale study have the potential to contribute to extracting and developing a context specific models to investigate the adoption of mobile cloud learning and other innovated technologies 
in developing countries. Also, it provides the potential adopters of ML a more accurate insight into adoption determinants to enhance their decision-making process. Furthermore, this study provides a valuable input to the industry providers of cloud computing services for more effective technology-specific marketing when introducing new cloud computing services. This information can be crucial for the development of effective marketing strategy of new projects of ML based on cloud computing.

\section{References}

[1] S. Bidin and A. A. Ziden, "Adoption and application of mobile learning in the education industry," Procedia-social and behavioral sciences, 90, pp. 720-729, 2013. https://doi.org/10.1016/j.sbspro.2013.07.145.

[2] M. Z. Alksasbeh, "Integrating mobile technology service quality, trust and cultural factors into technology acceptance of mobile learning," International Journal of Science, Innovation \& New Technology, 1(6), pp. 11 - 17, 2013.

[3] Y. Mehdipour and H. Zerehkafi, "Mobile learning for education: Benefits and challenges," International Journal of Computational Engineering Research, 3 (6), pp. 93-101, 2013.

[4] NIST, 24 Octobar 2018. [Online]. Available: https://www.nist.gov/programs-projects/nist-cloud-computing-program-nccp.

[5] Q. AlAjmi, R. A. Arshah, A. Kamaludin, A. S. Sadiq and M. Al-Sharafi, "A Conceptual Model of E-Learning based on Cloud Computing Adoption in Higher Education Institutions," in International Conference on Electrical and Computing Technologies and Applications (ICECTA), Ras Al Khaimah, United Arab Emirates, 2017. https://doi.org/10.1109/ICECTA.2017.8252013.

[6] B. McCrea, "IT on Demand: The Pros and Cons of Cloud Computing in Higher Education," Campus Technology, 2009.

[7] S. Tout, W. Sverdlik and G. Lawver, "Cloud computing and its securityin higher education." in Proceedings of ISECON, 26, Washington DC, 2009.

[8] B. Hirsch and J. W. Ng, "Education beyond the cloud: Anytime-anywhere learning in a smart campus environment." in Internet Technology and Secured Transactions (ICITST), International Conference (pp. 718-723). IEEE, 2011.

[9] H. T. Dinh, C. Lee, D. Niyato and P. Wang, "A survey of mobile cloud computing: Architecture, applications, and approaches," Wireless Communications and Mobile Computing, pp. 1587-1611, 2011. https://doi.org/10.1002/wcm.1203.

[10] S. Saidhbi, "A Cloud Computing Framework for Ethiopian Higher Education Institutions," Journal of Computer Engineering (IOSRJCE) ISSN: 2278-0661, ISBN: 2278-8727, 6 (6), pp. 01 - 09, 2012. https://doi.org/10.9790/0661-0660109.

[11] F. Al-Balushi, M. Bahari and A. Rahman, "Technology Organizational and Environmental (TOE) Factors Influencing Enterprise Application Integration (EAI) Implementation in Omani Government Organizations." Indian Journal of Science and Technology, 9(46), pp. 1 - 5, 2016.

[12] A. Saleh, S. M. Drus and S. S. Shariff, "Empirical Studies On Cloud Computing Adoption: A Systematic Literature Review," Journal of Theoretical \& Applied Information Technology, 95 (24), pp. 6809 - 6832, 2017.

[13] T. H. Davenport and L. Prusak, Information ecology: Mastering the information and knowledge environment, Oxford University Press on Demand, 1997.

[14] S. Jackson, "Organizational culture and information systems adoption: A three-perspective approach," Journal of Information and Organization, 21, pp. pp. 57-83, 2011. https://doi.org/10.1016/j.infoandorg.2011.03.003.

[15] A. Mukred, D. Singh and N. Safie, "Investigating the impact of information culture on the adoption of information system in public health sector of developing countries," International Journal of Business Information Systems, 24, pp. pp. 261-284, 2017. https://doi.org/10.1504/IJBIS.2017.082036.

[16] N. Sultan, "Cloud computing for education: A new dawn?" International Journal of Information Management, 30, pp. 109 - 116, 2010. https://doi.org/10.1016/j.ijinfomgt.2009.09.004.

[17] B.-N. Hwang, C.-Y. Huang and C. -L. Yang, "Determinants and their causal relationships affecting the adoption of cloud computing in science and technology institutions," Innovation, 18(2), pp. 164-190, 2016. https://doi.org/10.1080/14479338.2016.1203729.

[18] Z. M. Jawad, "Cloud Computing Adoption by Higher Education Institutions of Iraq: An Empirical Study," Journal of College of Education/Wasit, 1(28), pp. 591- 608, 2017. https://doi.org/10.31185/eduj.Vol1.Iss28.24.

[19] F. Makoza, "Cloud computing adoption in Higher Education Institutions of Malawi: An exploratory study," International Journal of Computing \& ICT Research, 9(2), pp. 37 - 54, 2015.

[20] T. -P. Liang, C. -W. Huang, Y. -H. Yeh and B. Lin, "Adoption of Mobile Technology in Business: a fit-viability model," industrial management and data systems, 107, pp. 1154 - 1169, 2007. https://doi.org/10.1108/02635570710822796.

[21] F. Mohammed, O. Ibrahim, M. Nilashi and E. Alzurqa, "Cloud computing adoption model for e-government implementation," information development, 33, pp. 303 - 323, 2017. https://doi.org/10.1177/0266666916656033.

[22] M. Masrom, "Technology acceptance model and E-learning," in 12th International Cinference on Education, 2007.

[23] H. M. Sabia, F. E. Uzoka, K. Langmia and F. N. Njeh, "Conceptualizing a model for adoption of cloud computing in education," International Journal of Information Management, 36 (2), pp. 183 - 191, 2016. https://doi.org/10.1016/j.ijinfomgt.2015.11.010.

[24] F. A. Herzallah, M. A. Al-Sharafi, Q. Alajmi, M. Mukhtar, R. A. Arshah and D. Eleyan, "Conceptualizing a Model for the Effect of Information Culture on Electronic Commerce Adoption," in Paper presented at the International Conference of Reliable Information and communcation technology, 2018. https://doi.org/10.1007/978-3-319-99007-1_80.

[25] V. Osubor and S. Chiemeke, "The impacts of information culture on e-learning innovation adoption in learning institiuations in Nigeria," African Journal of computing and ICT, pp. 17 - 26, 2015.

[26] M. Ginman, "Information culture and business performance," IATUL Quarterly, 2 (2), p. 93-106, 1988.

[27] B. Travica, "Influence of information culture on adoption of a self-service system," Journal of Information, Information Technology, and Organizations, 3, 2008. https://doi.org/10.28945/3270.

[28] B. Cronin and E. Davenport, "Social Intelligence," Annual Review of Information Science and Technology (ARIST), 28, pp. 3 - $44,1993$.

[29] C. Choo, P. Bergeron, B. Detlor and L. Heaton, "Information culture and information use: An exploratory study of three organizations," Journal of the Association for the Information Science and Technology, 59 (5), p. 792 - 804, 2008. https://doi.org/10.1002/asi.20797.

[30] A. K. Tjan, "Finally, a way to put your Internet portfolio in order," Harvard business review, vol. 79, pp. 76 - 85, 2001.

[31] D. Marchand, W. Kettinger and J. Rollins, Information Orientation: The Link to Business Performance, New York: Oxford University Press, 2001, pp. $213-236$.

[32] C. Furness, "Group Information Behavioural Norms and the Effective Use of a Collaborative Information System: A Case Study," 2010. [Online]. Available: https://tspace.library.utoronto.ca/bitstream/1807/26357/1/Furness_Colin_D_201011_PhD_thesis.pdf.

[33] A. Sinitsyna, "Impact of information culture and information behaviour on information quality," Business School Victoria University of Wellington, School of Information, 2014.

[34] Y. Ke, "Applying Marchand's information orientation theory to Sigma Kudos—an information product company," School of Computer Science, Physics and Mathematics Linnaeus University, 2011.

[35] R. Simons, Levers of Control: How Managers Use Innovative Control Systems to Drive Strategic Renewal, Boston: Harvard Business Press, 2013.

[36] A. Bhattacherjee, " Understanding information systems continuance: an expectation-confirmation model," MIS quarterly, 25, pp. 351-370, 2001. https://doi.org/10.2307/3250921.

[37] H. M. Sabi, F.-M. E. Uzoka, K. Langmia and F. N. Njeh, "Conceptualizing a model for adoption of cloud computing in education," International Journal of Information Management, 36 (2), pp. 183-191, 2016. https://doi.org/10.1016/j.ijinfomgt.2015.11.010.

[38] S. A. Haslam and C. McGarty, Research methods and statistics in psychology, Psychology Press, 2014.

[39] D. George and P. Mallery, SPSS for Windows Step by Step: A Simple Guide and Reference, 11.0 Update (4 ed.), Boston: Allyn and Bacon, 2003.

[40] J. Nunnally and I. Bernstein, Psychometric theory (3rd ed.), NewYork: McGraw-Hill, 1993. 
[41] J. F. Hair, W. C. Black, B. J. Babin and R. Anderson, Multivariate data analysis (7th ed.), Upper Saddle River, NJ, USA: Pearson Prentice Hall, 2010.

[42] D. Gefen and D. Straub, "A practical guide to factorial validity using PLS-Graph: Tutorial and annotated example," Communications of the Association for Information systems, 16 (1), 2005. https://doi.org/10.17705/1CAIS.01605.

[43] C. Fornell and D. F. Larcker, "Evaluating structural equation models with unobservable variables and measurement error," Journal of marketing research, 18 (1), pp. 39 - 50, 1981. https://doi.org/10.1177/002224378101800104 